\title{
Uveitis and Lyme borreliosis
}

\author{
J Breeveld, H Kuiper, L Spanjaard, L Luyendijk, A Rothova
}

\begin{abstract}
In a retrospective study 56 consecutive patients with uveitis of unknown origin and 56 consecutive patients suffering from uveitis of established aetiology were investigated. The purpose of this study was to determine the frequency of positive serological tests for Lyme borreliosis among patients with uveitis and to relate laboratory data to clinical findings. The antibody titre for Borrelia burgdorferi was determined by two assays: the indirect immunofluorescence assay and the enzyme linked immunosorbent assay. A positive result according to one or both assays was found for eight patients with uveitis of unknown aetiology (14\%) and three patients with uveitis of established cause $(5 \%)$. On clinical examination, none of the patients fulfilled the CDC criteria for diagnosis of Lyme borreliosis.
\end{abstract}

(Brf Ophthalmol 1993; 77: 480-481)

Ocular involvement in Lyme borreliosis is increasingly being recognised. Ocular manifestations may affect every tissue within the eye and orbit. ${ }^{12}$ Since there are no definite clinical diagnostic criteria for Lyme borreliosis and the interpretation of serological tests is difficult, the prevalence of Lyme borreliosis among patients with uveitis cannot be assessed accurately.

The purpose of this study was to determine the frequency of positive serological tests among patients with uveitis and to relate laboratory data to clinical findings.

Department of

Ophthalmology

Academic Medical

Centre, Amsterdam

J Breeveld

A Rothova

Department of Neurology, Academic Medical Centre, Amsterdam

H Kuiper

Department of

Bacteriology, Academic

Medical Centre,

Amsterdam

L Spanjaard

Department of

Ophthalmo-Immunology, The Netherlands Ophthalmic Research Institute, Amsterdam L Luyendijk

Correspondence to Josefine Breeveld, Department of Ophthalmology, Academic Medical Centre, Meibergdreef 9, $1105 \mathrm{AZ}$ Netherlands.

Accepted for publication 7 April 1993

\section{Patients and methods}

We retrospectively reviewed 56 consecutive patients with uveitis of unknown origin (group 1) and 56 consecutive uveitis patients with an established diagnosis (sarcoidosis, toxoplasmosis, HLA-related uveitis, Fuchs' heterochromic cyclitis (bilateral), acute retinal necrosis, cytomegalovirus retinitis, Posner-Schlossman syndrome) (group 2). For all patients the diagnostic examination included HLA-B27 typing, serological tests for syphilis (VDRL and TPHA), serum angiotensin converting enzyme, serum lysozyme, and chest $x$ rays. The diagnostic criteria for uveitis were those laid down by the International Uveitis Study Group. ${ }^{3}$

We performed a flagellum enzyme linked immunosorbent assay (ELISA) (Dakopatts, Denmark) for IgG antibodies against Borrelia burgdorferi. ${ }^{45}$ The assay was carried out according to the manufacturer's instructions.

Sera were also examined for $B$ burgdorferi antibodies by means of an indirect immunofluorescence assay (IFA). We followed the procedure described by Wilske et al with some modifications. ${ }^{6}$ The slides were coated with the
German skin isolate PKo (courtesy of Dr V Preac-Mursic, Munich) and incubated with the patient's serum and, after rinsing, with fluorescein conjugated antihuman immunoglobulin. Sera were not absorbed and a titre of 1:160 or higher was considered positive; a titre of 1:80 was considered borderline. All patients had negative VDRL and TPHA tests for syphilis. Patients with positive or borderline serological results were re-examined and questioned about their history, in particular about signs and symptoms associated with Lyme disease. Detailed ophthalmic examinations were performed to determine whether related ocular findings were present.

All patients with positive serological results and those with complaints suggesting Lyme disease were examined and evaluated by a neurologist who was experienced in the diagnosis and management of Lyme borreliosis.

We used the $\chi^{2}$ test for statistical analysis. A p value $<0.05$ was considered significant.

\section{Results}

The results of serological tests for anti-Borrelia antibodies among patients with uveitis are given in Table 1.

Eight patients (14\%) from the first group were positive, according to one or both assays, compared to three patients (5\%) of the second group (difference not significant). The established diagnoses for the latter were HLA-B27-related uveitis (two patients) and cytomegalovirus retinitis (one patient).

Manifestation of the uveitis in the eight patients of group 1 with anti-Borrelia antibodies varied. Three patients had anterior, four had intermediate, and one had posterior uveitis. In the course of the disease five patients developed anterior vitritis with vitreal strings and 'snowball' infiltrates. No other specific symptoms were observed. None of the patients with positive serological results fulfilled CDC criteria for Lyme borreliosis. ${ }^{7}$ The patient who was found positive by both assays was referred with posterior uveitis of the left eye. Visual acuity was 0.2 left eye and 1.0 right eye. Ocular findings for the affected left eye consisted of papillitis, vasculitis, a focal chorioretinitis lesion, and cystoid macular oedema. No abnormalities were

Table 1 Lyme serology among patients with uveitis

\begin{tabular}{lcc}
\hline & $\begin{array}{l}\text { Uveitis of } \\
\text { undetermined } \\
\text { aetiology } \\
(n=56)\end{array}$ & $\begin{array}{l}\text { Uveitis of } \\
\text { established } \\
\text { aetiology } \\
(n=56)\end{array}$ \\
Serological test results & 1 & 0 \\
\hline Positive IFA and positive ELISA & 5 & 1 \\
Positive IFA but negative ELISA & 1 & 0 \\
Marginal IFA and positive ELISA & 1 & 2 \\
Negative IFA but positive ELISA & 10 & 2 \\
Marginal IFA but negative ELISA & 10 & 51 \\
Negative IFA and negative ELISA & 38 & \\
\hline
\end{tabular}


present in the right eye. There were no tick bites, erythema migrans, or other manifestations compatible with Lyme borreliosis in the patient's history.

Of all patients tested, $90(80 \%)$ were negative according to both ELISA and IFA: 38 of 56 (68\%) patients from group 1 (uveitis of unknown origin) and 51 of $56(93 \%)$ patients of group 2 . A marginally positive titre was found by IFA five times more often for the first group compared with the second (10 patients in group 1 and two patients in group 2) and accounts for the observed difference between the two groups. None of these patients had Lyme borreliosis according to $\mathrm{CDC}$ criteria.

\section{Discussion}

In this study we obtained a positive test result for anti-Borrelia antibodies for 11 of 112 patients (10\%), but none had Lyme borreliosis according to $\mathrm{CDC}$ criteria.

Approximately one third of patients with uveitis were reported to be positive for antiBorrelia antibodies compared to $5-10 \%$ of the controls. ${ }^{8}$ However, the interpretation of serological test results is very difficult and depends on the type of test used and the research environment. ${ }^{89}$ False positive and false negative serological reactions occur regularly, mainly due to cross reactions with other types of spirochaetes, the most important being Treponema pallidum. ${ }^{10}$ False positive reactions have also been reported in autoimmune diseases and infectious mononucleosis. ${ }^{11}$ Negative test results may be obtained in an early stage of the infection; seronegative disease also exists. ${ }^{12}$

There are several explanations for the presence of anti-Borrelia antibodies in patients with uveitis. Firstly, a positive test may be due to polyclonal B cell activation, thus representing a false positive test reaction. The second possibility is that the presence of anti-Borrelia anti- bodies is the result of a past infection with $B$ burgdorferi and is therefore not related to the ocular disease. Finally, in patients positive for anti-Borrelia antibodies uveitis might be a solitary sign of Lyme borreliosis. In the future detailed analyses, including polymerase chain reactions in intraocular fluid, may bring the answer to these questions. ${ }^{13}$

On the basis of this study, we conclude that Lyme borreliosis is not a frequent cause of uveitis. Assays for anti-Borrelia antibodies during the initial screening of patients suffering from uveitis are of very limited value.

1 Winterkorn JMS. Lyme disease. Neurologic and ophthalmic manifestations. Surv Ophthalmol 1990; 35: 191-204.

2 Seidenberg NB, Leits ML. Orbital myositis with Lyme disease. Am f Ophthalmol 1990; 109: 13-6.

3 Bloch-Michel E, Nussenblatt RB. International uveitis study roup recommendations for the evaluation of intraocula inflammatory disease. Am $\mathcal{F}$ Ophthalmol 1987; 103: 234-6.

4 Hansen K, Hindersson P, Pedersen NS. Measurements of antibodies to the Borrelia burgdorferi flagellum improves serodiagnosis in Lyme disease. $\mathcal{F}$ Clin Microbiol 1988; 26: 338-46.

5 Hansen K, Asbrink E. Serodiagnosis of erythema migrans and acrodermatitis chronica atrophicans by the Borrelia burgdorferi flagellum enzyme-linked immunosorbent assay. burgdorfen flagellum enzyme-linked

6 Wilske B, Schierz G, Preac-Mursic V, Weber K, Pfister HW, Einhaupl $\mathbf{K}$. Serological diagnosis of erythema migrans disease and related disorders. Infection 1984; 5: 331-7.

7 Ciesielski CA, Markowitz LE, Horsley R, Hightower AW, Russell $\mathrm{H}$, Broome CV. Lyme disease surveillance in the United States, 1983-1986. Rev Infect Dis 1989; 11 (suppl 6): 1435-41.

8 Isogai $\mathrm{E}$, Isogai $\mathrm{H}$, Kotake $\mathrm{S}$, Yoshikawa $\mathrm{K}$, Ichijshi $\mathrm{A}$, Kosaka S, et al. Detection of antibodies against Borrelia burgdorferi in patients with uveitis. Am F Ophthalmol 1991; 112: $23-30$.

9 Rosenbaum JT, Rahn DW. Prevalence of Lyme disease among patients with uveitis. Am $\mathcal{f}$ Ophthalmol 1991; 112 . among

10 Magnarelli LA, Anderson JF, Johnson RC. Cross-reactivity in serological tests for Lyme disease and other spirochetal infections. F Infect Dis 1987; 156: 183-8.

11 Craft JE, Grodzicki RL, Steere AC. Antibody response in Lyme disease: evaluation of diagnostic tests. $\mathcal{F}$ Infect $D i$ 1984; 149: 789-95.

12 Dattwyler RJ, Volkman DJ, Luft BJ, Halperin JJ, Thomas J, Golightly MG. Seronegative Lyme disease dissociation of specific T- and B-lymphocyte responses to Borrelia burgdorferi. N Engl F Med 1988; 319: 1441-6.

13 Keller TL, Halperin JJ, Whitman M. PCR detection of Borrelia burgdorferi DNA in cerebrospinal fluid of Lyme neuroborreliosis patients. Neurology 1992; 42: 32-42. 